\title{
Probabilistic approach of the Upper and Middle Odra basin daily rainfall modeling
}

\author{
Marcin Wdowikowski ${ }^{1,}$, Andrzej Kotowski ${ }^{2}$, Pawet B. Dąbek ${ }^{3}$, and Bartosz Kaźmierczak ${ }^{2}$ \\ ${ }^{1}$ Institute of Meteorology and Water Management - National Research Institute, 01-673 Warsaw, \\ Podlesna Street 61, Poland \\ ${ }^{2}$ Wrocław University of Science and Technology, Faculty of Environmental Engineering, Wybrzeze \\ Wyspianskiego 27, 50-370 Wroclaw, Poland \\ ${ }^{3}$ Institute of Environmental Protection and Development, Wrocław University of Environmental and \\ Life Sciences, Poland pl. Grunwaldzki 24, 50-363 Wroclaw, Poland
}

\begin{abstract}
The aim of this study was to obtain the maximum daily rainfall descriptions based on 9 probability distributions in 12 meteorological stations located in Upper and Middle Odra river basin. Analysis included long-term period from 1961 to 2010. Regarding to AIC and BIC informational criterions Gamma distribution that appeared to be best fitted probability distribution to measurement rainfall data series. For several stations, Pareto, Weibull and generalized exponential distributions were also possible to use. For practical purposes it is necessary to carry out a similar analysis for much shorter rainfall intervals. The final evaluation of the suitability of individual probability distributions for constructing maximum rainfall probabilistic models requires further research.
\end{abstract}

\section{Introduction}

The reliability of urban drainage systems is not fully achievable due to the random nature of precipitation. However, it must be designed in the way that fulfill the contemporary standards of drainage, which is defined as the adaptation of the system to receive the maximum (predicted) storm water streams with a frequency of appearance equal to the acceptable (socially acceptable) frequency of spillage into the terrain [1]. Recent extreme natural phenomena, such as intense or long-lasting rainfall, as well as more frequent river floods or urban floods, caused with significant economic losses. That is why it is so important to systematically obtain rainfall analysis, including the determination of the statistical incidence of their maxima's [2].

The Blaszczyk model, based on rainfall measurements from the turn of the 19th and 20th centuries, is formally recommended to design drainage systems of urbanized areas in Poland, which is criticized by the scientific community. More and more often new models of maximum rainfall are used, such as Kupczyk-Suligowski or Bogdanowicz-Stachy regional models. New models, for various reasons, gives much higher rainfall values compared to the Blaszczyk formula. Due to practical reasons, in Poland, it is urgent to

*Corresponding author: marcin.wdowikowski@imgw.pl 
replace the rainfall model of Blaszczyk's, in the dimensioning of drainage systems of terrains, with more accurate models (local impact models). The identification of differences in the results of papers published in the last two decades is also needed.

Both the synthetic description of the maximum rainfall structure as well as the probabilistic modelling of maximum precipitation based on the long term period used in climate analysis (eg 50 years) for the Upper and Middle Odra river basin, is currently not referenced in the problematic literature. At the same time, studies that presents a comparative analysis of a large number of probability distribution models is also insufficient. The scientific papers published in Poland in the case of spatio-temporal variability includes shorter periods of analyzed data or smaller number of measurement points (eg Polish Atlas of Climate for the 1971-2000 period [3], Maximum rainfall in Poland [4], Heavy and torrential rainfall during 1954-1981 in Poland [5] or Projections of changes in precipitation extremes in Poland [6]). Likewise, other parameters (eg flood indicators [7]) were analyzed and the maximum precipitation was limited to selected catchment areas or geographic regions (eg Widawa or Nysa Klodzka [8, 9]) or even individual measurement points (eg Agrometeorological Observatory in Swojec [10]). For the maximum precipitation modelling purposes, the literature of the subject presents the application of only selected probability distributions that can be used to characterize heavy rainfall in very general way (eg Blaszczyk's model) or only with very local impact (eg. in Cracow [11], Lodz [12] Czestochowa [13], Kielce and Kielce Uplands [14], Warsaw [15] or Wroclaw $[1,2,16])$. The main reason for this was the limited access of researchers to IMWM-NRI database or analysis conducted on their own measurement network.

The main aim of this study is to present the possibility of using the different probability distributions for maximum precipitation modeling in the Upper and Middle Oder basin, ie in the area in Poland that is often affected by the occurrence of extreme values. As the research material were used daily precipitation recorded in between 1961 and 2010 at 12 IMWM-NRI meteorological stations (from Cieszyn to Slubice). Maximum daily precipitation were described by the probability distributions most commonly recommended in hydrology, such as Gamma and Weibull distributions, and the GED distribution recommended by Kotowski and Kaźmierczak [1, 2, 16, 17, 18]. The quality of fitting the theoretical to empirical rainfall distributions will be assessed on the basis of the $A I C$ and $B I C$ information criteria.

\section{Study area and methods}

\subsection{Odra river basin}

The Upper and Middle Oder Basin was the research area. Odra is one of the largest rivers in the catchment of the Baltic Sea, and after the Vistula it is the second largest river in Poland.

The basin covers the administrative regions of the Silesian, Opole, Lower Silesia, Wielkopolska and Lubusz voivodeships. The length of the river is $854 \mathrm{~km}$ in total, including $742 \mathrm{~km}$ in Poland, and $204 \mathrm{~km}$ in the Lower Silesian voivodeship (from Olawa $\mathrm{km} 216+500$ to Glogow km $392+900)$. Oder springs are located in the Czech Republic in the Odreckie Vrchachy, at an altitude of $634 \mathrm{~m}$ a.s.1. On the whole length of the Odra river can be divided into two parts: the mountain, the first $50 \mathrm{~km}$ (Upper Oder), and the lowland the remaining part (Middle and Border Oder). From Kedzierzyn-Kozle to Brzeg Dolny Odra it is channeled at $186 \mathrm{~km}$, in details it is built with 24 stages of waterlogging, including 23 permanently navigable in the navigation season (usually from 15th March to 15 th December). The difference between the water level between the beginning and the end 
of the channel is about $64 \mathrm{~m}$. In the distal Odra flows freely and its current is regulated with a spike. The extreme precipitation values occurrence, especially the maximum values, significantly determine the water relations of the Oder River Valley and directly contribute to the emergence of dangers from violent floods and floods in urban areas $[1,7,19,20]$. Long-term regional rainfall causes over-retention of the soil and the formation of increased surface runoff in the catchments. According to the authors of the study [19], more than $75 \%$ of the floods in the Oder River are recorded after prolonged and intense rain events. Occurrence of water from river beds causes local flooding (spring period) or widespread floods (in 1997) or larger floods in the Oder River (2001, 2006, 2010 or 2013), which is a consequence of the increasing of heavy rainfall in this region. The increasing tendency of intensive rainfall occurrence in the Upper and Middle Oder basin, as well as the potential effects of urban floods (Wroclaw, Legnica, Klodzko, Głogow, etc.) and in the main catchment areas (Kwisa, Bobr, Kaczawa) became the main reason of authors interest upon this subject. Odra flooding has also significant impact for hydrogeological droughts in lowland part of basin [20].

\subsection{Measurement stations}

Research material used in the work were rainfall daily data series from 50 years (1961-2010), derived from 12 IMWM-NRI measurement stations. The daily totals from the characteristic points of the Upper and Middle Oder basin, represented by regional and climatological stations, also are used to prepare meteorological forecasts and statements, including short media releases (press, radio and television). The location of meteorological stations in the analyzed river basin, taking into account the terrain, presented in Figure 1 and their characteristics are given in Table 1.

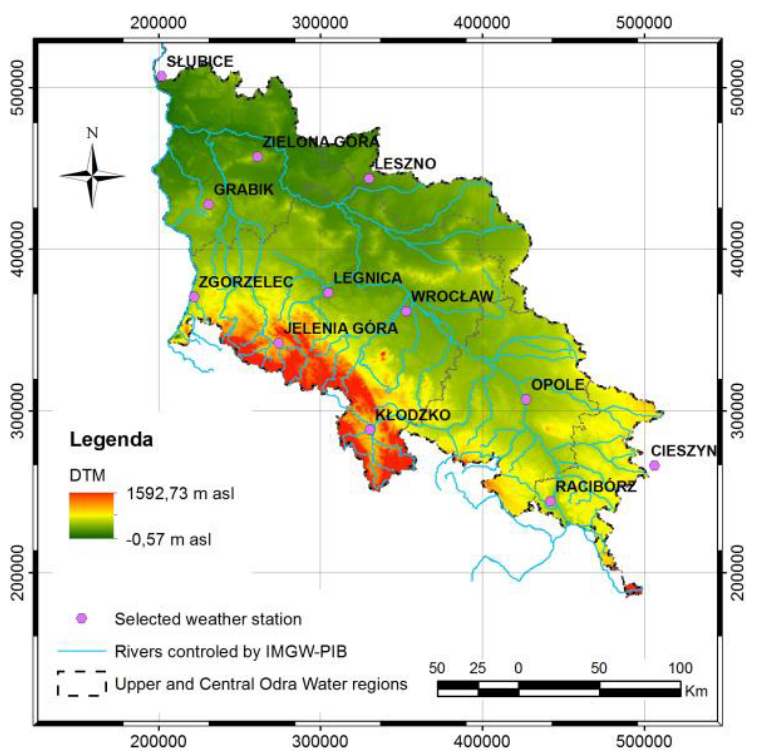

Fig. 1. Location of meteorological stations IMGW-PIB in Upper and Middle Oder (own elaboration, based on PUWG-92 coordinate system).

The digital terrain model (DTM) was used to visualize the terrain (Fig. 1). The free terrain data was obtained from the Central Office of Geodesy and Cartography (CODGIK).

Figure 2 shows the spatial distribution of the highest precipitation levels recorded at particular meteorological stations between 1961 and 2010 (based on Table 1). Spatial 
distribution uses the Inverse Distance Weighting (IDW) estimation method conducted in geostatic ArcGIS software.

Table 1. Characteristics of IMWM-NRI meteorological stations in Upper and Middle Oder basin Indications: $\mathrm{H}$ - elevation, $\mathrm{h}_{\mathrm{d}, \max }$ - maximum daily precipitation $\mathrm{h}_{\mathrm{R}, \min }$ - minimum annual precipitation $\mathrm{h}_{\mathrm{R}, \max }$ - maximum annual precipitation $\mathrm{h}_{\mathrm{R}, \mathrm{av}}$ - average annual precipitation in years 1961-2010.

\begin{tabular}{|l|c|c|c|r|c|c|c|}
\hline Station & Attitude & Latitude & $\begin{array}{c}\mathbf{H} \\
{[\mathbf{m} \text { a.s.l. }]}\end{array}$ & $\begin{array}{c}\mathbf{h}_{\mathbf{d}, \mathbf{m a x}} \\
{[\mathbf{m m}]}\end{array}$ & $\begin{array}{c}\mathbf{h}_{\mathbf{R}, \mathbf{m i n}} \\
{[\mathbf{m m}]}\end{array}$ & $\begin{array}{c}\mathbf{h}_{\mathbf{R}, \max } \\
{[\mathbf{m m}]}\end{array}$ & $\begin{array}{c}\mathbf{h}_{\mathbf{R}, \mathbf{a v}} \\
{[\mathbf{m m}]}\end{array}$ \\
\hline Raciborz & 181127 & 500340 & 206 & 92.9 & 443 & 1001 & 642 \\
\hline Cieszyn & 186492 & 497550 & 295 & 129.5 & 640 & 1348 & 934 \\
\hline Opole & 175812 & 503740 & 165 & 99.0 & 374 & 868 & 624 \\
\hline Klodzko & 163651 & 502613 & 356 & 101.2 & 369 & 586 & 602 \\
\hline Wroclaw & 165357 & 510614 & 120 & 74.4 & 381 & 776 & 596 \\
\hline Legnica & 161227 & 511133 & 122 & 85.9 & 361 & 795 & 537 \\
\hline Jelenia Gora & 154720 & 505401 & 342 & 119.3 & 462 & 1005 & 698 \\
\hline Zgorzelec & 150131 & 510810 & 203 & 81.1 & 346 & 809 & 616 \\
\hline Leszno & 163205 & 515009 & 91 & 79.2 & 349 & 733 & 547 \\
\hline Zielona Gora & 153128 & 515549 & 192 & 80.0 & 385 & 770 & 587 \\
\hline Grabik & 150641 & 513909 & 165 & 90.2 & 380 & 902 & 627 \\
\hline Slubice & 143711 & 522055 & 53 & 132.5 & 361 & 861 & 566 \\
\hline
\end{tabular}

Analyzing the characteristics of maximum daily and annual precipitation (min and max) and annual averages from given long-term period (Table 2), it is clear that the maximum daily precipitation typically account for about $10 \%$ of the largest annual precipitation and almost $50 \%$ of annual minimum precipitation.

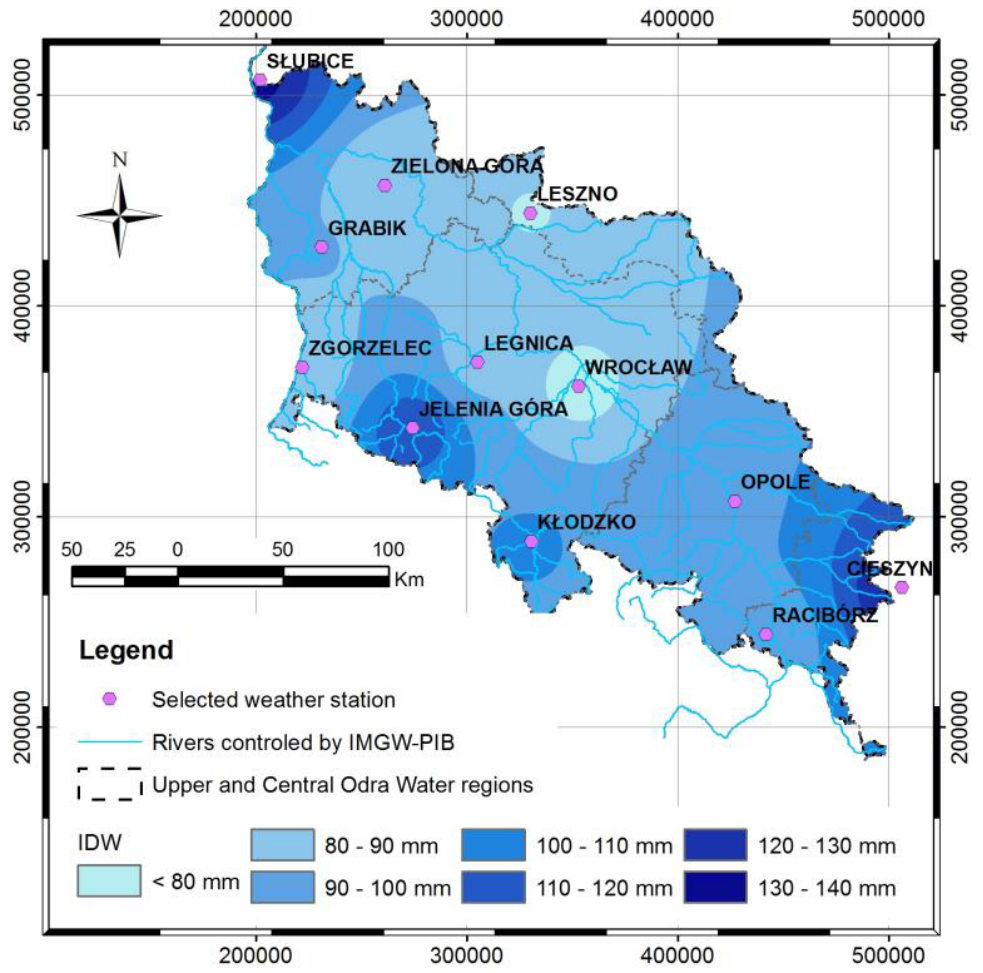

Fig. 2. Spatial variability of the daily precipitation in the years 1961-2010 (own elaboration, based on PUWG-92 coordinate system). 


\subsection{Probability distributions and its fitting to measurement data}

According to the principles of modeling of maximum precipitation patterns, widely described by Kotowski $[1,2,16,17]$, the highest values of daily precipitation (h) for each measurement station were determined for the purpose of measuring data series. This procedure is not limited to the criterion of the highest value in a given year (AMS annual maximum series), because it may result that a significant precipitation value that could have occurred at least twice in the same year, may be excluded. So prepared in that way elements of the random variable were sorted decreasing, and then they were assigned empirical probability of exceedance, from $p=0.02$ (for the highest value) to $p=0.98$ (for the smallest value), according to the formula:

$$
p(m, N)=m /(N+1)
$$

where: $m$ - The position (number) of the random sample element in the descending order, $N$ - number of random samples.

In literature $[1,2]$, the concept of precipitation in years $\mathrm{C}$ is often used in the quantitative description of precipitation, interchangeably with the probability of occurrence of precipitation, which is described by a simple relation:

$$
C=100 / p
$$

The theoretical probability distributions used in hydrology were used to describe measurement data. Table 2 lists the distributions and the abbreviations used in the study.

Table 2. Analyzed probability distributions.

\begin{tabular}{|c|c|c|c|}
\hline No. & Distribution & Abbreviation & Parameters \\
\hline 1 & Pearsona typu III (Gamma) & P3 & 3 \\
\hline 2 & Fischera-Tippeta typ I (Gumbel) & EV1 & 2 \\
\hline 3 & Fischera-Tippeta typ II (Frechet) & EV2 & 3 \\
\hline 4 & Fischera-Tippeta typ III (Weibull) & EV3 & 3 \\
\hline 5 & Logarytmiczno-Normalny & LN & 3 \\
\hline 6 & Uogólniony Pareto & GPA3 & 3 \\
\hline 7 & Uogólniony wartości ekstremalnych & GEV & 3 \\
\hline 8 & Uogólniony wykładniczy & GED & 3 \\
\hline 9 & Logarytmiczno-logistyczny & LLOG & 3 \\
\hline
\end{tabular}

Estimators of the parameters of individual distributions were determined by the maximum loglikelihood estimation method (MLE), by numerical maximization of the logarithm of the loglikelihood functions, taking into account the range of variability of the scaled parameters of the scale, shape and location - in the case of tree parameters distributions and scale and shape - in the case of the Gumbel (EV1) distribution [1, 2, 16, $17,18]$. In the numerical process of maximizing the logarithm of likelihood function with respect to the parameters of the analyzed distributions, the following assumptions are assumed: the scale parameter must be greater than zero; the shape parameter must be different from zero, and the location parameter as the lower limit assumes the lowest value of the decreasing ordered data serie. Using the logarithm of the likelihood function, the quality of fitting the theoretical distributions to the measured data was described using the $B I C$ - Bayesian information criterion of Schwartz and AIC - the Akaike information criterion, givenby the following formulas:

$$
\begin{aligned}
& B I C=-2 \ln L+k \ln N \\
& A I C=-2 \ln L+2 k
\end{aligned}
$$


where: $L$ - analyzed random sample logarithm of the likelihood function, $k$ - number of estimated parameters and $N$ - number of random samples.

Necessary numerical calculations performed using the R- package statistical modules ('FAdistr', 'fExtremes', 'MASS' and 'bbmle').

\section{Results}

Based on the accepted methodology, the series of maximum daily rainfall totals from the analyzed stations were analyzed (Table 1). The obtained theoretical distributions were compared with the empirical distributions of the measured data using (3) and (4) as shown in Tables 3 and 4, respectively. In both cases, the smallest values were shown, which shows the greatest correlation between the theoretical distributions and the measured data.

Table 3. Values of $A I C$ informational criterion for analyzed probability distributions and meteorological stations.

\begin{tabular}{|l|l|l|l|l|l|l|l|l|l|}
\hline \multicolumn{1}{|c|}{$\boldsymbol{A I C}$} & P3 & EV1 & LN & EV3 & GPA3 & GEV & LLOG & GED & EV2 \\
\hline Słubice & & & & & & & & & \\
\hline Zielona Góra & & & & & & & & & \\
\hline Legnica & & & & & & & & & \\
\hline Leszno & & & & & & & & & \\
\hline Wrocław & & & & & & & & & \\
\hline Jelenia Góra & & & & & & & & & \\
\hline Kłodzko & & & & & & & & & \\
\hline Opole & & & & & & & & & \\
\hline Racibórz & & & & & & & & & \\
\hline Cieszyn & & & & & & & & & \\
\hline Grabik & & & & & & & & & \\
\hline Zgorzelec & & & & & & & & & \\
\hline
\end{tabular}

Table 4. Values of $B I C$ informational criterion for analyzed probability distributions and meteorological stations.

\begin{tabular}{|l|c|c|c|c|c|c|c|c|c|}
\hline \multicolumn{1}{|c|}{$\boldsymbol{B I C}$} & P3 & EV1 & LN & EV3 & GPA3 & GEV & LLOG & GED & EV2 \\
\hline Słubice & 362.44 & 416.36 & 374.78 & 353.94 & 372.50 & 379.42 & 375.17 & 370.99 & 379.42 \\
\hline Zielona Góra & 344.22 & 360.12 & 354.94 & 344.22 & 350.60 & 356.83 & 356.52 & 348.84 & 356.83 \\
\hline Legnica & 346.77 & 369.08 & 364.39 & 357.99 & 358.29 & 367.35 & 366.74 & 358.31 & 367.35 \\
\hline Leszno & 343.39 & 367.38 & 354.19 & 353.12 & 350.27 & 357.82 & 356.06 & 349.15 & 357.82 \\
\hline Wrocław & 353.25 & 360.38 & 355.78 & 354.58 & 352.23 & 358.32 & 358.14 & 353.31 & 358.32 \\
\hline Jelenia Góra & 371.30 & 406.14 & 389.76 & 383.96 & 385.04 & 393.44 & 391.23 & 382.31 & 393.44 \\
\hline Kłodzko & 366.95 & 406.14 & 390.09 & 370.43 & 395.05 & 397.20 & 391.83 & 377.96 & 397.20 \\
\hline Opole & 313.47 & 383.88 & 353.15 & 325.60 & 350.28 & 358.15 & 353.95 & 342.89 & 358.15 \\
\hline Racibórz & 299.98 & 353.61 & 319.37 & 310.22 & 317.07 & 323.19 & 320.13 & 316.39 & 323.19 \\
\hline Cieszyn & 404.19 & 430.57 & 425.39 & 411.61 & 414.57 & 429.55 & 427.75 & 410.36 & 429.55 \\
\hline Grabik & 340.12 & 362.29 & 359.52 & 349.70 & 349.22 & 362.37 & 366.65 & 350.02 & 362.37 \\
\hline Zgorzelec & 368.45 & 391.50 & 380.52 & 370.61 & 373.29 & 385.72 & 383.10 & 368.15 & 385.72 \\
\hline
\end{tabular}

The AIC and BIC values generally have similar values, and it ranged from 294.25 to 426.76 for AIC's and from 299.98 to 430.57 for BIC's. According to both indicators, the Gamma (P3) distribution most accurately describes the maximum daily precipitation for the analyzed stations. In the vast majority of cases, there is also a relatively small difference in the value of the information criteria between the P3 and GED distributions. In details, in the case of the Slubice station, EV3 distribution became the best described in terms of precipitation data, whereas in case of Wroclaw station, despite the indication of GPA3 distribution as the best, P3 and GED distributions are also possible. For Zielona Gora 
station, the AIC and BIC values for P3 and EV3 are identical, indicating the probability of using both probability distributions to describe measurement data and the need for additional ratings indicators. It is noteworthy that the values of the AIC and BIC information criteria for the assumed assumptions give the same results for the GEV and EV2 distributions, moreover, these are high values indicating relatively limited possibilities of their use to describe the measurement data. Figure 3 shows a spatial interpretation of the research results, which were the potential possibility of using the analyzed probability distributions to describe the maximum daily precipitation that occurred in the Upper and Middle Oder basins, based on the data in Tables 3 and 4.
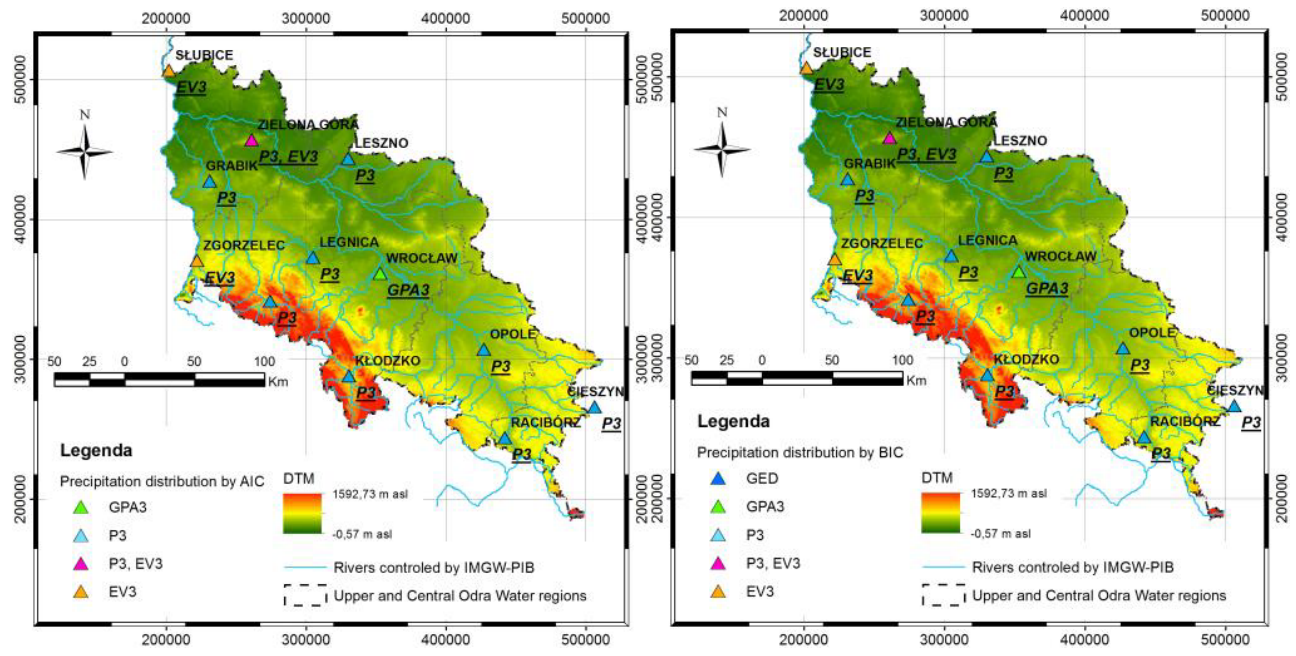

Fig. 3. Best fitted probability distributions for analyzed meteorological stations in the Upper and Middle Odra basin regarding to AIC (from right) and BIC (from left) informational criterion (own elaboration, based on PUWG-92 coordinate system).

\section{Conclusions}

In order to describe the maximum daily precipitation from 1961 to 2010 (Table 1, Figure 1) at 12 measurement stations in the Upper and Middle Odra basin, a 9 probability distributions (Table 2) were used. For the analyzed area and the rainfall duration of 1440 minutes (measured in rigid intervals, between 6 UTC hours), the theoretical distribution of the most accurate measurement data from the studied stations turned out to be the vast majority of cases (9 out of 12) was Gamma distribution (P3). This allows to formulate a general conclusion that this is the best distribution for describing the daily rainfall precipitation in the Upper and Middle Oder area for the examined time series. Similar results were obtained by Kaźmierczak and Wdowikowski [21] for data from Legnica, Wdowikowski with the team [23] for data in the Lusatian Neisse basin (western part of the Upper and Middle River Basin) and earlier by Krężałek with the team [22] for data from Wroclaw, Legnica, Leszno, Zielona Gora and Slubice. All authors analyzed daily rainfall data from the same period of 1961-2010 [22]. Depending on the accepted information criterion AIC or BIC (Figures 3 and 4), in several cases, it was also possible to use the following:

- three-parameter generalized Pareto distribution (GPA3) for Wroclaw (meets both criteria);

- Weibull (EV3) three-parameter distribution for Slubice and Zielona Góra (meets both criteria), as well as for Zgorzelec (according to AIC), 
- three-parameters generalized exponential distribution (GED) for Zgorzelec (according to BIC).

The investigated and presented spatial variation of the suitability of analyzed probability distributions for daily rainfall modeling indicates that it is possible to apply both distribution of the entire river basin district - Gamma distribution (P3), as well as description of measurement data from individual locations with different probability distributions (for example, Gamma (P3) and Weibull (EV3) for Zielona Gora).

However, for practical purposes, ie to achieve the highest quality rainfall modeling results, a similar analysis should be performed for significantly shorter periods of time. Researches from Kotowski and Kaźmierczak [1, 16] done for data from Wroclaw or Kaźmierczak and Wdowikowski [21] for data from Legnica, where the time intervals were analyzed from 5 minutes to 3 or 6 days, clearly indicate that the suitability of individual probability distributions for varied rainfall durations may be different. The authors, however, state that the assessment of the suitability of individual probability distributions within different time intervals for the construction of probabilistic rainfall models is essential for modern way of thinking about maximum rainfall modeling, especially in probabilistic approach. Further and more detailed researches in this matter should be conducted.

\section{References}

1. A. Kotowski, The principles of safe dimensioning of sewer systems (Seidel-Przywecki, Warsaw, 2015)

2. A. Kotowski, B. Kaźmierczak, A. Dancewicz, The modeling of precipitations for the dimensioning of sewer systems (Polish Academy of Sciences, Warsaw, 2010)

3. H. Lorenc, Climate atlas of Poland (The Publishing House of the Institute of Meteorology and Water Management, Warsaw, 2005)

4. E. Bogdanowicz, J. Stachý, Maximum rainfall in Poland. Design characteristics (The Publishing House of the Institute of Meteorology and Water Management, Warsaw, 1998)

5. A. Żyromski, Heavy and torrential rain in 1954-1981 in Poland (Seidel-Przywecki, Warsaw, 2008)

6. I. Pińskwar, Projection of precipitation extremes in Poland (The Publishing House of the Water Management Commete in NAoS, Warsaw, 2010).

7. W. Szalińska, I. Otop, T. Tokarczyk: Meteorology Hydrology and Water Management 2, 1 (2014)

8. M. Wdowikowski, Indicative assessment of precipitation structure in Widawa basin (The Publishing House of the Institute of Environmental Protection of Technical University of Wroclaw, Wroclaw, 2014)

9. I. Otop, Opera Corcontica, 41 (2004).

10. P. Licznar, J. Łomotowski, Environmental Protection, 27, 1 (2005)

11. R. Twardosz, Daily atmospheric precipitation in synoptic and probabilistic terms on the example of Cracow (1886-2002) (The Publishing House of the Institute of Geography and Spatial Management of the Jagiellonian University, Kraków, 2005)

12. M. Zawilski, A. Brzezińska, Urban Water Journal, 11, 7 (2014)

13. M. Mrowiec, Gaz, Woda i Technika Sanitarna, 7 (2014) 
14. R. Suligowski, Maximum rainfall depth of specified duration and probability of exceedance in Kielce (The Publishing House of the Hydrological Commission of the Polish Geographical Society, Kielce, 2014)

15. P. Licznar, P. Szeląg, Environmental Protection 36, 3 (2014)

16. B. Kaźmierczak, A. Kotowski, J Hydrol 525 (2015)

17. S. Coles, An introduction to statistical modeling of extreme values (Springer Series in Statistics, Springer-Verlag, London, 2001)

18. W. L. Shinyie, N. Ismail, A. A. Jemain, Water Resour Manag 28, 11 (2014)

19. P. Migoń, Exceptional natural events in Lower Silesia and their effects. (The Publishing House of the Institute of Geography and Regional Development of the University of Wrocław, Wrocław, 2010)

20. J. Kubicz, P.B. Dąbek, Acta Sci. Pol. Formatio Circumiectus 15, 4 (2016)

21. B. Kaźmierczak, M. Wdowikowski, Periodica Polytechnica Civil Engineering 60, 2 (2016)

22. K. Krężałek, T. Szymczak, B. Bąk, Woda-Środowisko-Obszary Wiejskie 13, 4 (2013)

23. M. Wdowikowski, B. Kaźmierczak, O. Ledvinka, Meteorology Hydrology and Water Management, 4, 1 (2016) 